\title{
The Moderation Effects of Perceptions of Organizational Politics on the Relationship between Work Stress and Turnover Intention: An Empirical Study about Civilian in Skeleton Government of China*
}

\author{
Guangjin Zhang ${ }^{1}$, Gabriel Lee ${ }^{2}$ \\ ${ }^{1}$ Politics and Law School, China University of Geosciences (CUG), Wuhan, China; ${ }^{2}$ College of Business, City University of Hong \\ Kong (CityU), Hong Kong, China. \\ Email: hbzgj@126.com, hbwhlee@yeah.net
}

Received May $26^{\text {th }}, 2010$; revised July $5^{\text {th }}, 2010$; accepted August $19^{\text {th }}, 2010$.

\begin{abstract}
It is disastrous for organization that valued employee leave their jobs. Many researches have found that work stress is consistently and strongly related to intentions to turnover. Therefore, studying buffers of the stress-turnover intention relationship is important. This paper examines the situational variables such as perceptions of organizational politics, as moderators of the stress-turnover relationship. An investigation from 304 employees in Chinese skeleton government found that: lower levels of perceived politics will minimize turnover intentions resulted from work stress. These findings are helpful to understand the unique relationships between these variables and provide specific information for managers to retain valued employees.
\end{abstract}

Keywords: Perceptions of Organizational Politics, Work Stress, Turnover Intention, Moderation Effects

\section{Introduction}

Employees are recognized as a very important organizational asset, Organizational cost incurred due to employees quitting their jobs and the subsequent hiring of replacement personnel, new-hire training, and general costs for administration can be tremendous in terms of personal, work unit and organizational re-adjustments [1]. Thus, voluntary employee turnover is an important organizational issue that merits thorough exploration.

Although it is recognized that people leave their jobs for a variety of reasons, there is consistent research evidence indicating that voluntary turnover can be explained by employees' intention to leave the organization. In investigations of turnover, actual voluntary turnover measures are extremely difficult to obtain; therefore, in-

*This research was supported by the Primary Research Foundation of University belonging to Education Ministry of china under Grant CUGW090211, the Research Project of S\&T of Hubei province under Grant B20080402, and the Humanity Social Science Foundation of Hubei province under Grant 2008y054. tentions to turnover are used in the high majority of turnover studies, as these intentions are the only antecedent that has been consistently found to be a direct antecedent to actual turnover. Like those prior works, this study explores voluntary turnover by focusing on the potential impact of employees' intentions to leave the organization.

The prediction and understanding of employee turnover has been studied from many different perspectives. Most of the past studies have focused on single direct antecedents and examined their roles in the context of process models of turnover. Work stress has been identified as major contributors to voluntary turnover and has ultimately been blamed for the loss of employees. On the other hand, many models acknowledge that negative affective reactions (such as work stress) do not necessarily cause individuals to actually quit and have attempted to improve their predictive ability by incorporating factors outside the individual. Consequently, researchers have attempted to better understand these variations by con- 
sidering the effects of external variables such as job alternatives, social support, and the quality of leader member exchange (LMX) relationships.

Despite these variations, the stress-turnover relationship is well established and can have negative bottomline consequences for an organization [2]. Thus, it remains important to investigate how other variables influence this relationship. Specifically, other variables often provide additional insight or clarification into the exact nature of how the variables interact. The intention of this study is to examine situational variables that might affect the stress-turnover intention relationship. In particular we are interested in understanding variables that have the potential to buffer or intensify the impact of stress on employees' intentions to leave the organization. The variable of interest in the study is perceptions of politics (POPs). We expect that by studying buffers of stress impact on turnover intentions, we can gain a better understanding of internal organizational dynamics that affect individuals and organizations as a whole. Thus, the purpose of this study is to investigate how POPs moderate the relationship between work stress and turnover intentions.

\section{Literature Review and Hypothesis}

\subsection{Work Stress-Turnover Relationship}

The stress-turnover relationship has received considerable attention and has been empirically supported in different contexts, worker types, and cultures [3]. Past studies suggest that one factor related to turnover is tension associated with the employees' present work, This conceptualization is in keeping with the prior established notion that increasing levels of tension in the current job may lead to a decision to quit the stressful work environment. Additionally, Cao Yu-ping used causal modeling to find support for the notion that stress is a predictor of turnover [4]. This has led to a general acceptance that the relationship exists and has likely led to a decrease in the number of studies on this topic.

As suggested by the cybernetic theory of stress, it is important to note that not all individuals who experience workplace stressors have the resulting stress and not all people who experience stress have the adverse resulting outcomes (i.e., turnover intentions) [5]. Some studies have investigated gender, age, tenure, and other personality variables which may influence the stress-turnover relationship, but a number of variables have been neglected. In particular, we feel that it is necessary to examine not only variables related to the person, but also aspects of the organization. Up to this point, there are no known studies that have explicitly examined situational factors unique to the social milieu of the organization such as organizational climate, perceived organizational support, perceived politics, and organizational justice perceptions to name a few.

\subsection{Perceptions of Organizational Politics}

Organizational politics is defined as "social influence attempts directed at those who can provide rewards that will help promote or protect the self-interest of the actor". Although we recognize that politics can have some constructive outcomes in organizations, it is generally (and in the large majority of research studies) recognized that political behavior deals with attempts to benefit, protect or enhance ones self-interest without regard for the welfare of the organization or others. Thus, the theory in this article is based on Mintzberg's definition that describes political behavior as individual or group behavior that is informal, ostensibly parochial, typically divisive and illegitimate [6]. In keeping with this definition, our measure of perceptions of politics really does not address positive aspects of this construct. Additionally, since it is difficult to observe or measure politics or political behaviors, individuals can report their perceptions of such activities (i.e., POPs).

In the original conception, Ferris et al. suggested that POPs led directly to job anxiety/stress and to different forms of organizational withdrawal, including turnover. In a revised model of POPs, Ferris et al. expanded the model on POPs, but still retained the linkages between POPs and stress and POPs and turnover. These relationships have been examined and empirically supported in numerous investigations [7].

Whereas POPs have been examined as a direct antecedent to these outcomes, it has received minimal attention as a potential moderator. The only study we are aware of investigating POPs as a moderator examined how it influenced the conscientiousness job performance relationship [8]. This leads to a natural question of what other relationships POPs might influence as a moderating variable. This question is especially relevant to the POPsstress-related relationships since POPs has only been considered as a direct antecedent in such relationships. Moreover, the direct relationship between POPs and stress has generally been substantiated [9]. This study expands the literature by considering and examining an alternative pattern of the POPs-stress relationship.

\subsection{POPs as a Moderator of the Stress-Turnover Intention Relationship}

Although it has been established that POPs are independently related to stress and lead to higher self-reports of turnover intentions [10], the interactive effect of work 
stress and POPs has never been examined. This is surprising due to the fact that their combined influence is likely to provide greater insight into the specific prediction of turnover intentions.

Previous studies have examined the link between an individual perceiving the workplace as political and various outcomes, including intentions to turnover. Results indicate that there is a positive relationship between political perceptions and individuals' intentions to depart from an organization. The reason for this is that POPs is considered as a disconcerting phenomenon that decrease an individual's desire to remain in a political workplace [11].

In some cases organizational politics are perceived as threatening. When individuals experience stress and the resulting feelings of wanting to leave the organization (i.e., turnover intentions), political situations are likely to intensify these feelings. Due to the nature of organizational politics, people are also less likely to feel that they have reliable external coping mechanisms. Once politics is perceived, individuals tend to view the workplace as a selffocused environment characterized by self-serving behavior [10]. It is argued that this kind of self-reliance and forced individualism diminishes peoples' ability to deal with workplace stressors and the resulting stress, and increases their desire to escape from undesirable situations [12]. Thus, the following hypothesis is proposed:

Hypothesis: Perceptions of organizational politics will moderate the relationship between stress and turnover intentions, specifically the positive relationship between stress and turnover intention will be strongest when perceptions of politics are highest.

\section{Conclusions}

\subsection{Samples}

The respondents were 304 civilian (40\% response rate) from skeleton government in Hunan province of china. The sample was primarily male (57\%). The years of education ranged from 15 to 22 with a mean of 17 years. Tenure with the organization was measured categorically to protect respondents' anonymity, the departments divided into two types, the one is outer oriented that provide service for the public; the other is internal oriented managing internal personnel and hardware construction. The demographics for the sample have some of representative.

\subsection{Measures}

All of the items on the survey were responded to on a fivepoint Likert scale. The anchors for the scale were strongly disagree (1) to strongly agree (5). The items in the scales for each sample were averaged to create an overall mean for each variable. The items were coded such that high values represented high levels of the constructs.

Perceptions of organizational politics were measured with fifteen items $(\mathrm{a}=.87)$ developed by Kacmar and Carlson [13]. A sample item from this scale was "People in this organization attempt to build them up by tearing others down".

Job stress was measured with the seven-item scale $(\alpha$ $=.89$ ) from Rizzo, House and Lirtzman [14]. A sample item included "I work under a great deal of tension".

Turnover intention was measured with three items $(\alpha$ $=.84$ ) from Seashore, Lawler, Mirvis and Cammann [15]. A sample item from this scale was "I will probably look for a new job in the near future".

\subsection{Control Variables}

Four demographic variables were controlled in this study. The variables were tenure, gender, education background and department. The first three control variables were included because previous research has shown the strong impact these variables can have on turnover intentions [1]. Department was included to eliminate any differences that might exist between individuals in different departments of the organization.

\section{Data Analysis and Results}

We used hierarchical moderated regression analysis (HMRA) to test our hypotheses. There were four steps in the HMRA. In the first step, control variables were entered. Stress was entered in the second step, and the moderating variable (POPs) was entered in the third step. In the final step, the interaction term was entered.

Table 1 presents means, standard deviations, and inter-correlations for the variables. As can be seen in Table $\mathbf{1}$, it provided further evidence for the study, the correlation between stress and turnover intentions was significant $(r=.382, \rho<.01)$. Additionally, the moderators-perceptions of politics significantly related to turnover intentions $(\mathrm{r}=.430, \mathrm{p}<.01)$.

Since all of the data used in this study were collected from the same individuals, at the same time, and using the same method, common method variance (CMV) posed a potential threat to the results of this study. Before proceeding with further analyses, we tested for CMV using the Harmon one-factor test [16], where all of the scales in the study were submitted to an exploratory factor analysis (EFA). CMV exists when there is only one factor or the first factor explains a majority of the variance. The results of this EFA using principal components analysis produced multiple factors with Eigenvalues equal to or greater than 1.00 , and the first factor explained only $29 \%$ of the variance. Thus, the Harmon onefactor test indicates that CMV was not a serious problem in this study. 
Table 1. Means, standard deviations, and inter-correlations.

\begin{tabular}{ccccccccc}
\hline & Mean & S.D. & 1 & 2 & 3 & 4 & 5 & 6 \\
\hline 1. Tenure & 2.84 & 1.29 & & & & & & \\
2. Gender & 1.44 & 0.5 & -.050 & & & & & \\
3. Education & 16.8 & 5.14 & $-.323^{* *}$ & $-.212^{* *}$ & & & & \\
4. Department & 1.16 & 0.41 & -.031 & $.135^{* *}$ & .010 & & & \\
5. Work stress & 2.91 & 0.91 & $.137^{* *}$ & $-.061^{*}$ & $-.054^{*}$ & -.013 & & \\
6. POPs & 3.20 & 0.70 & $.106^{* *}$ & .048 & $-.061^{*}$ & $.133^{* *}$ & $.451^{* *}$ & $.030^{* *}$ \\
7. Turnover intention & 2.39 & 1.10 & $-.140^{* *}$ & $-.156^{* *}$ & $-.170^{* *}$ & .036 & $.382^{* *}$ & .436 \\
\hline
\end{tabular}

$* \mathrm{P}<0.05 ; * *<0.01$

Table 2. Hierarchical moderated regression analysis predicting turnover intention.

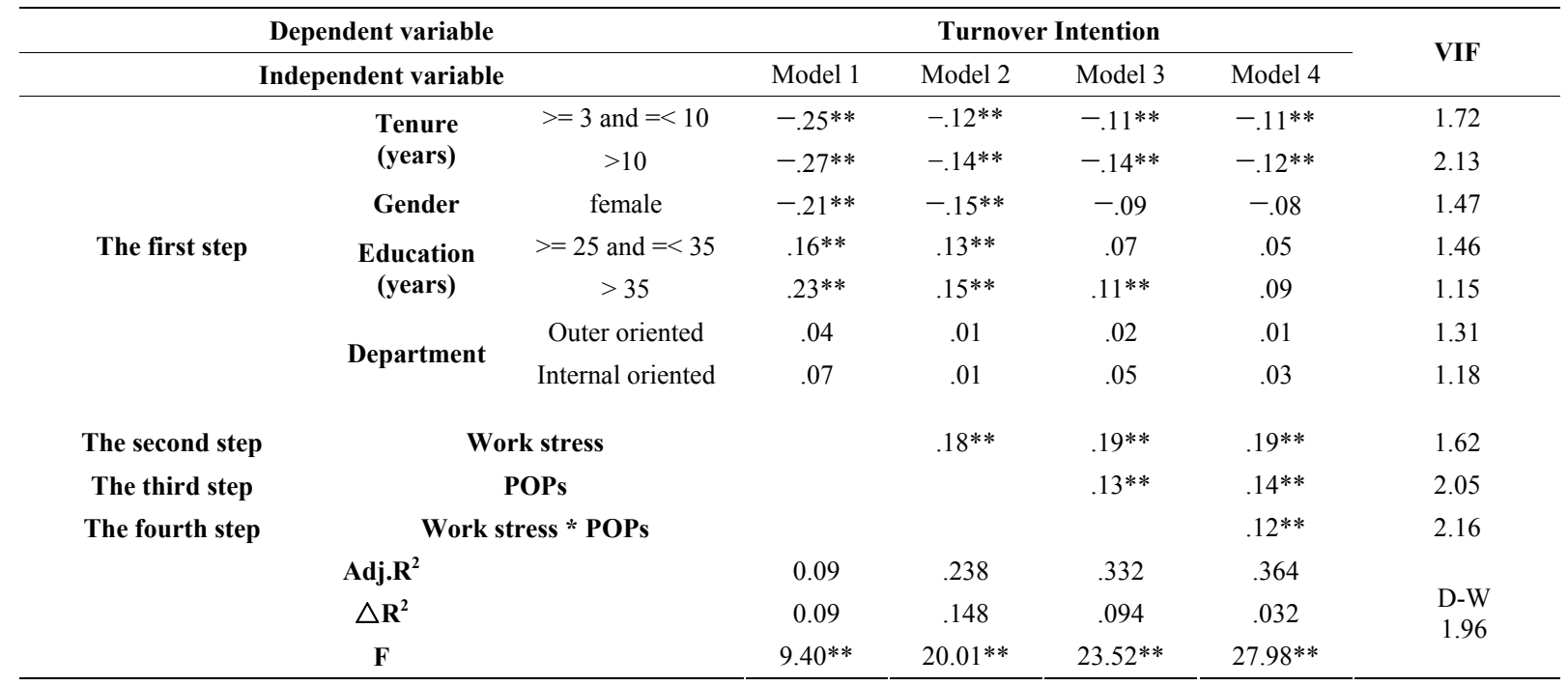

$$
* *<0.01
$$

Table 2 provides the results from the HMRA. Results from the analyses showed that the control variable department was not significantly related to turnover intentions, whereas tenure, gender, and education were all related, specifically, tenure and female is negatively related to turnover intention, and education is positively related to it. Which maybe resulted form that internal governments lack for competition compared with outer society, the civilian who has more tenure within governments would have less courage to enter into market system accompanied with competition, most of the female also like stable and middle-high reward offices position, In general, the more education, the more capability, the more chance to acquire a new job, therefore, the higher turnover intention. The control variables explained 9\% variance. In the second step, work stress was positively and significantly related to turnover intentions, and explained additional $14.8 \%$ of variance beyond the control variables. In step three, the POPs was significantly related to turnover intentions, and POPs explained 9.4\% unexplained variance. Finally, in the fourth step, we entered the interaction terms and found support for hypothesis as it was positively and significantly $(\beta=.12, \mathrm{p}$ $<.01)$ related to turnover intentions, further, the interaction term explained an additional $3.2 \%$ of the variance beyond the first three steps. The final column of Table 2 showed the VIF and the Durbin-Watson in Model 4, the biggest VIF is the interaction term (2.16), which indicated that the predicators haven't serious multiple collinearity, the $\mathrm{D}-\mathrm{W}$ is $1.96(\approx 2)$, it indicated that the error items in model 4 are independent.

A graphical representation of this relationship is provided in Figure 1 and illustrates how individuals with high stress and high POPs exhibit the strongest turnover intention. Of particular interest are the low levels of turnover intention when POPs are low, regardless of 


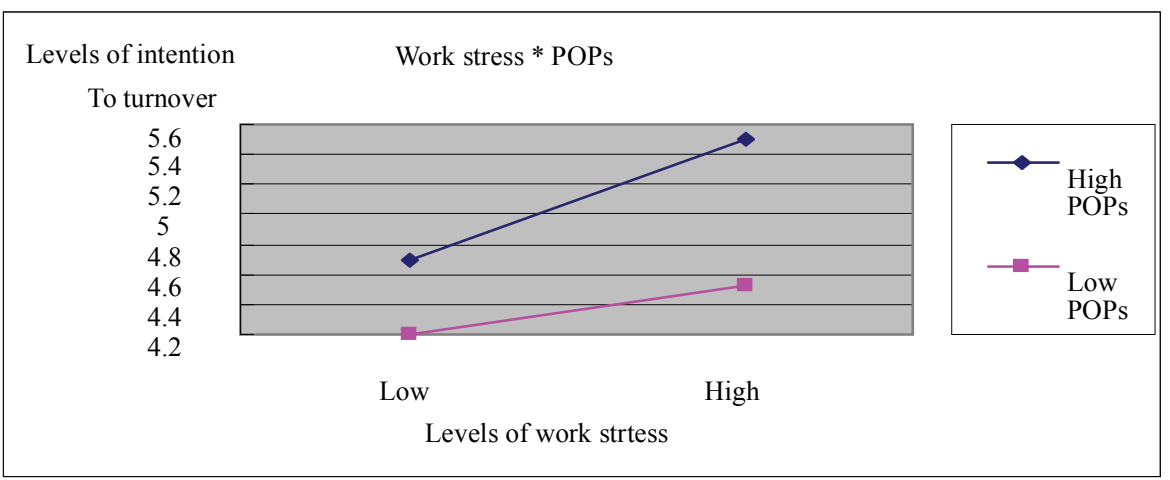

Figure 1. Graphical representation of perceptions of politics moderating the work stress-turnover intention relationship.

level of work stress, but the same does not hold when POPs are high. Specifically, when stress is low and POPs are high, turnover intention is moderate, but when both variables are high the resulting turnover intention is considerably higher than for any other combination of the two variables.

\section{Conclusions and Discussions}

\subsection{Findings}

The results from this study provide support for the study's hypothesis. That is POPs moderates the relationship between work stress and turnover intentions. Although individuals may experience work stress, which could lead to turnover intentions, this positive relationship is strongest when political perceptions are the highest (see Figure 1). Thus, when POPs are at low levels, turnover intentions are considerably lower. The finding points that the importance of organizations promoting desired behaviors and discouraging self interested behaviors that epitomized politics [9].

\subsection{Implications for Management Practice}

Organizations are inherently stressful places. There are a number of different workplace stressors that ultimately produce stress for employees. If we are to acknowledge that workplaces do and will continue producing stress, it is necessary for organizations and their managers to find ways to reduce the negative consequences from this felt stress. The findings from this study found that this can be accomplished in this way. That is, managers can attempt to reduce perceptions of politics. Politics have been identified as a source of stress themselves [9], but it may be that if managers can decrease political perceptions, they can decrease the negative feelings and behavioral intentions from work stress. Some ways to decrease political perceptions are to make rules and procedures, ensure that they are understood, and then to enforce them [12].
Clearly establishing and enforcing rules for appropriate behavior leaves little room for alternative interpretations. Managers need to consistently reward desired behaviors that follow the guidelines and ignore and/or punish behavior that does not. If good things only come to those individuals who follow the rules, employees will quickly learn and enact behaviors that will reap rewards, and in this process, lower individuals' levels of perceptions of politics.

\section{REFERENCES}

[1] P. W. Hom and R. W. Griffeth, "Employee Turnover," South/Western Ohio, Cincinnati, 1995.

[2] S. Parasuraman, "Predicting Turnover Intentions and Turnover Behavior - A Multivariate Analysis," Journal of Vocational Behavior, Vol. 21, No. 1, 1982, pp. 111-121.

[3] X. P. Zhao, L. Liu and C. Z. Zhang, "A Multi-Variables Analysis on Factors Influencing Employee's Turnover Intention," China Soft Science, Vol. 18, No. 3, 2003, pp. 71-73.

[4] Y. P. Cao, "A Review of Occupational Stress, Burnout and Departure Intention among University Faculty," Journal of Shanxi Finance and Economics University, Vol. 27, No. 3, 2005, pp. 41-44.

[5] J. R. Edwards, "A Cybernetic Theory of Stress, Coping, and Well-Being in Organizations," Academy of Management Review, Vol. 17, No. 2, 1992, pp. 238-274.

[6] H. Mintzberg, "Structure in Fives: Designing Effective Organizations," Prentice-Hall, Englewood Cliffs, New York, 1983.

[7] Z. D. Huang, "A Literature Review about Perception of Organizational Politics in Foreign Country," Foreign Economics and Management, Vol. 26, No. 3, 2004, pp. 15-18.

[8] W. A. Hochwarter, L. A. Witt and K. M. Kacmar, "Perceptions of Organizational Politics as a Moderator of the Relationship between Conscientiousness and Job Performance," Journal of Applied Psychology, Vol. 85, No. 3, 2000, pp. 472-478. 
[9] K. M. Kacmar, D. P. Bozeman, D. S. Carlson and W. P. Anthony, "A Partial Test of the Perceptions of Organizational Politics Model," Human Relations, Vol. 52, No. 3, 1999, pp. 383-416.

[10] G. R. Ferris, G. Harrell-Cook and J. H. Dulebohn, “Organizational Politics: The Nature of the Relationship between Politics Perceptions and Political Behavior," In: S. B. Bacharach and E. J. Lawler, Eds., Stamford Research in the Sociology of Organizations, Vol. 17, JAI Press, New York, 2000.

[11] R. S. Cropanzano, J. C. Howes, A. A. Grandey and P. Toth, "The Relationship of Organizational Politics and Support to Work Behaviors, Attitudes, and Stress," Journal of Organizational Behavior, Vol. 18, No. 2, 1997, pp. 159-180.

[12] G. R. Ferris, G. Adams, R. W. Kolodinsky, W. A. Hochwarter and A. P. Ammeter, "Perceptions of Organ- izational Politics: Theory and Research Directions," In: F. Daiisereau and F. J. Yammarino, Eds., Research in MultiLevel Issues, Elsevier Science/JAI Press, Oxford, 2002.

[13] K. M. Kacmar and D. S. Carlson, "Further Validation of the Perceptions of Politics Scale (Pops): A Multiple Sample Investigation," Journal of Management, Vol. 23, No. 5, 1997, pp. 627-658.

[14] J. R. Rizzo, R. J. House and S. I. Lirtzman, "Role Conflict and Ambiguity in Complex Organizations," Administrative Science Quarterly, Vol. 15, No. 2, 1970, pp. 150-163.

[15] S. E. Seashore, E. E. Lawler, P. Mirvis and C. Cammann, "Observing and Measuring Organizational Change: A Guide to Field Practice," Wiley, New York, 1982.

[16] P. M. Podsakoff and D. W. Organ, "Self-Reports in Organizational Research: Problems and Prospects," Journal of Management, Vol. 12, No. 4, 1986, pp. 531-544. 